\title{
Experimental Study of Brittle Behavior of Clay Shale in Rapid Triaxial Compression
}

\section{Journal Article}

\section{Author(s):}

Amann, Florian; Kaiser, Peter; Button, Edward Alan

Publication date:

2011-01

Permanent link:

https://doi.org/10.3929/ethz-b-000042039

Rights / license:

In Copyright - Non-Commercial Use Permitted

Originally published in:

Rock Mechanics and Rock Engineering 45(1), https://doi.org/10.1007/s00603-011-0195-9 


\title{
Experimental Study of Brittle Behavior of Clay Shale in Rapid Triaxial Compression
}

\author{
Florian Amann • Peter Kaiser · Edward Alan Button
}

Received: 12 April 2011/Accepted: 11 August 2011/Published online: 2 November 2011

(C) Springer-Verlag 2011

\begin{abstract}
The brittle failure behavior of an over-consolidated clay shale (Opalinus Clay) in undrained rapid triaxial compression was studied. The confining stress levels were chosen to simulate the range of confining stresses relevant for underground excavations at the Mont Terri Underground Research Laboratory, and to investigate the transition from axial splitting failure to macroscopic shear failure. Micro-crack initiation was observed throughout the confining stress range utilized in this study at a differential stress of 2.1 MPa on average, which indicates that friction was not mobilized at this stage of brittle failure. The rupture stress was dependent on confinement indicating friction mobilization during the brittle failure process. With increasing confinement net volumetric strain decreased suggesting that dilation was suppressed, which is possibly related to a change in the failure mode. At confining stress levels $\leq 0.5 \mathrm{MPa}$ specimen rupture was associated with axial splitting. With increasing confinement, transition to a macroscopic shearing mode was observed. Multi-stage triaxial tests consistently showed lower strengths than
\end{abstract}

\footnotetext{
F. Amann ( $\square)$

Institute of Geology, Engineering Geology, Swiss Federal

Institute of Technology, Zurich, Sonneggstrasse 5,

8092 Zurich, Switzerland

e-mail: florian.amann@erdw.ethz.ch

P. Kaiser

Center for Excellence in Mining Innovation,

936 Ramsey Lake Road, Sudbury, Canada

e-mail: pkaiser@miningexcellence.ca

\section{E. A. Button}

Formally-Institute of Geology, Engineering Geology,

Geoconsult Pvt. Ltd. India, Sonneggstrasse 5,

8092 Zurich, Switzerland

e-mail: edward.button@geoconsult.eu
}

single-stage tests, demonstrating cumulative damage in the specimens. Both the Mohr-Coulomb and Hoek-Brown failure criteria could not satisfactorily fit the data over the entire confining stress range. A bi-linear or S-shaped failure criterion was found to satisfactorily fit the test data over the entire confinement range studied.

Keywords Opalinus Clay - Brittle failure - Clay shale · Frictional strength mobilization · Crack initiation

\section{Introduction}

Under compressive loading conditions, brittle rocks undergo failure by a complex process of micro-crack initiation, damage accumulation, and crack coalescence (failure localization), eventually leading to rupture with a combination of tensile and shear failure processes (Bieniawski 1967; Brace et al. 1966; Scholz 1968; Cook 1965; Lajtai and Lajtai 1974; Martin 1997; Diederichs 2003). When the confining stress $\left(\sigma_{3}\right)$ is zero or very low, macroscopic failure is typically associated with axial splitting. As $\sigma_{3}$ is increased, the failure process transitions to macroscopic shear failure (Brace et al. 1966; Jaeger 1960; Hallbauer et al. 1973; Kaiser and Kim 2008). At the microscale both types of failure can in large part be attributed to tensile fracturing (Lajtai et al. 1990). As $\sigma_{3}$ increases the micro-fracturing processes change, resulting in different macroscopic failure modes (Paterson 1958). Several laboratory studies on artificial materials with inclined preexisting flaws under uniaxial and biaxial compressive loading conditions were utilized to investigate the influence of $\sigma_{3}$ on fracture propagation and the resulting failure mode. Hoek (1965) used plates of annealed glass containing open elliptical flaws and showed, that the stable crack 
length increases with decreasing ratio of applied principal stresses $\left(\sigma_{3} / \sigma_{1}\right.$, Fig. 1). The stable crack length increased rapidly when the principal stress ratios dropped below 0.05 , i.e., when the confinement was very small. These results suggest that confinement suppresses the growth of propagating tensile micro-cracks. Analytical models for Mode I fracture propagation utilizing linear elastic fracture mechanics were developed, based on the assumption of a sliding crack (Ashby and Hallam 1986; Kemeny and Cook 1986; Germanovich and Dyskin 1988) or based on a spherical pore (Sammis and Ashby 1986). These models are able to reproduce the experimental results obtained by Hoek (1965).

Horii and Nemat-Nasser (1985) used plates of Columbia Resin containing pre-existing straight thin flaws of different sizes. In the absence of confining stress, cracks emanated from large and compliant flaws and grew parallel to the axial stress direction. The specimen failed by axial splitting. When confining stresses were applied, the first cracks emanated at the tips of large and compliant flaws, but these cracks were soon arrested. At later stages of biaxial loading some smaller flaws suddenly nucleated cracks. These cracks grew spontaneously in an unstable manner even without axial stress increase, and ultimately formed a macroscopic shear failure zone (Horii and NematNasser 1985).

Bobet and Einstein (1998) investigated the fracture coalescence in gypsum with two non-aligned, open, or closed pre-existing flaws under uniaxial and biaxial compression. The tests showed two types of propagating fractures: tensile wing cracks and secondary cracks, which initiated as shear cracks in a plane roughly co-planar with the flaws. Wing cracks appeared under unconfined and slightly confined compressive loads and disappeared entirely at high confining stresses. Secondary cracks

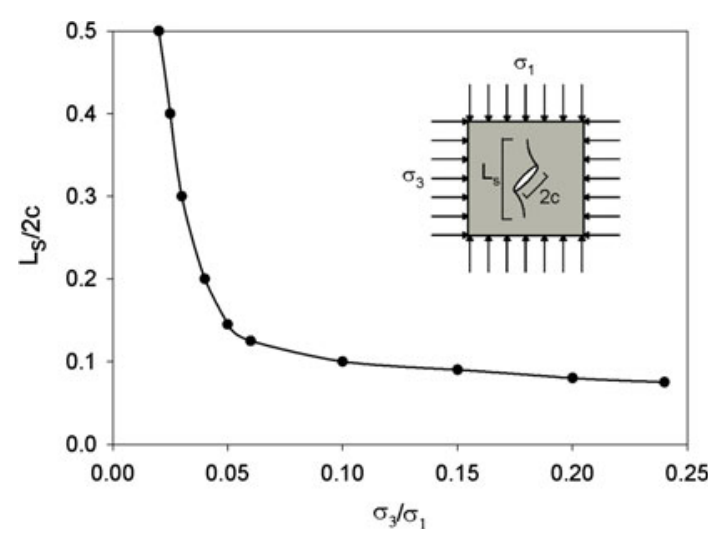

Fig. 1 Relationship between stable crack length $\left(L_{\mathrm{S}}\right)$ and ratio of applied stresses as observed under biaxial loading conditions of plates of annealed glass containing an open elliptical flaw (modified after Hoek $1965 ; 2 c=$ length of initial open crack) occurred at all confinement conditions and were involved in crack coalescence. Coalescence of initially stable growing cracks was usually observed when the growth of secondary crack became unstable.

These experimental and analytical studies collectively show that $\sigma_{3}$ has a strong influence on fracture propagation, the stable length of propagating fractures, the mode of fracturing, and explain the transition from axial splitting to macroscopic shear failure observed on rock specimens as confinement is increased. The change in the macroscopic failure mode is possibly associated with a change in the stable length of propagating tensile micro-cracks (Hoek 1965), and a change in propagation mode from dominant tensile fracturing to fracturing accommodating rotation of crack-bound rock fragments leading to shear failure with the associated mobilization of friction (Bobet and Einstein 1998).

Kaiser and Kim (2008) re-evaluated uniaxial and triaxial laboratory data obtained by Evert Hoek on igneous, metamorphic, and sedimentary rocks. They compared the measured unconfined compressive strength (UCS) with the apparent unconfined compressive strength (ACS; Steiner et al. 2010) obtained by linear back-extrapolation of triaxial strength data from the high confinement range (Fig. 2). The ACS was typically 1.5-1.8 times larger than the measured UCS. Kaiser and Kim (2008) suggested that brittle failure processes tend to get suppressed when $\sigma_{3}$ is increased beyond a threshold confining pressure. They also showed that the required axial stress causing rupture increased substantially at confining stresses around UCS/ 10. For $\sigma_{3}$ larger than approximately UCS/10, failure was typically associated with macroscopic shear failure. The principal stress ratio $\sigma_{3} / \sigma_{1}$ at the transition from axial splitting to macroscopic shear failure obtained by Kaiser and Kim (2008), referred to as the spalling limit by Kaiser

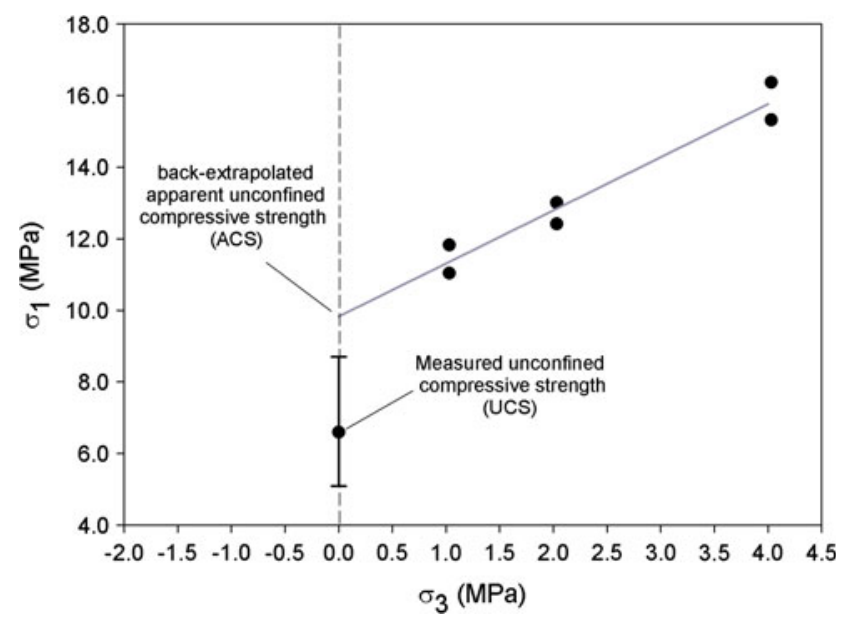

Fig. 2 Definition of the back-extrapolated apparent unconfined compressive strength (ACS) 
et al. (2000), was between 0.05 and 0.07 . This range in principal stress ratio is close to the ratio associated with the rapid increase in the stable crack length observed by Hoek (1965) on annealed glass. These experimental results on brittle rock specimens showed a strong influence of confining stress on the brittle failure processes and the resulting failure envelop, which has to be considered in constitutive laws for rock undergoing brittle failure.

Amann et al. (2011) conducted uniaxial compressive strength tests on Opalinus Clay (OPA) and showed that this over-consolidated clay shale fails in brittle manner under unconfined compression. It was also shown that rupture of the clay shale in unconfined compression was related to cumulative damage (defined by inelastic strain as a consequence of loading) which is initiated at a relatively consistent crack initiation stress threshold $\left(\sigma_{\mathrm{CI}}\right)$, followed by fracture coalescence involving axial cracks and bedding-parallel side-steps. Consequently, the ultimate rupture surface was typically inclined at $70-80^{\circ}$ from horizontal. The motivation of the experimental study presented here is to analyze the failure processes of OPA under low-tomoderate confinement conditions as encountered in the near-field around underground excavations.

\section{Description of Opalinus Clay (OPA)}

For this study, over-consolidated Opalinus Clay specimens from the shaly facies (Thury and Bossart 1999) of the Mont Terri Underground Laboratory (URL) were obtained. According to Underwood (1967) this rock is classified as clay shale. The mass fractions of the pre-dominant mineralogical components of the shaly facies are clay minerals (50-66\%), quartz (10-20\%), carbonates (8-20\%) and feldspar (3-5\%) (Thury and Bossart 1999; Klinkenberg et al. 2009). The mass fraction of clay minerals is composed of 20-30\% 2:1 layer and mixed layer silicates, 7-8\% chlorite and 20-25\% Kaolinite (Klinkenberg et al. 2009). Clay platelets are tabular-shaped and sub-parallel with the macroscopic bedding made up of siderite concretions and silt and sandstone lenses. Spatially distributed coarse grains in OPA were identified as carbonate bioclasts (shell fragments) and pyrite (trace fossils) of different shapes and size (up to $1 \mathrm{~mm}$ ), orientated typically sub-parallel to the bedding (Klinkenberg et al. 2009). The pronounced microfabric of the clayey matrix was formed by sedimentation and a complex history of burial, physical compaction, development of diagenetic bonding, tectonic faulting, uplift, and erosion (Marschall et al. 2005). The maximum burial depth at the level of the Mont Terri URL is estimated to be $1,000 \mathrm{~m}$ in the late Tertiary; the present burial depth is 200-300 m (Thury and Bossart 1999). Due to the compaction of clay minerals, the physical properties (e.g., hydraulic conductivity, strength, seismic velocity) of the clay shale are anisotropic.

The mass fraction of water of OPA is $5.6 \%$ with a standard deviation of $0.8 \%$ (Bock 2008), and the porosity varies between 12 and $18 \%$. Mercury porosimetry data suggest that a large portion of the pores consists of equivalent pore radii in the micro- (equivalent radius $<25 \mathrm{~nm}$ ) and macro-scale (equivalent radius $>25 \mathrm{~nm}$ ). The fraction of macro-pores is estimated to be about $10 \%$ (Marschall et al. 2005).

\section{Sampling and Testing Methods}

\subsection{Sampling, Specimen Characterization and Specimen Handling}

Drillcores of Opalinus Clay (core diameter $89 \mathrm{~mm}$ ) were obtained from two $60^{\circ}$ inclined boreholes (BRC-3, $25 \mathrm{~m}$ in length, and BRC-4, $20 \mathrm{~m}$ in length) in the shaly facies at the Mont Terri URL utilizing triple-tube core barrels. The boreholes were drilled with compressed air cooling. The cores were hermetically sealed in vacuum-evacuated foil. Cylindrical specimens were carefully prepared by dry cutting and polishing the end faces in a lathe. Depending on the original specimen length and texture, a height-todiameter ratio of 1.4 to 2.0 was obtained. The remaining pieces of each core were used to determine the mass fraction of water by weighing and drying at $105^{\circ} \mathrm{C}$ to constant weight following ISRM (1979) suggested methods. The volumetric water content and the total porosity were determined as described in Amann et al. (2011).

Prior to testing, a petro-physical description of each specimen was obtained. The P-wave velocity was determined in both the axial and lateral directions. The tests were usually conducted about $30 \mathrm{~min}$ after removal of the hermetically sealed packing to minimize changes in state and potential damage due to water loss.

After each test the inclination of the macro-scale failure surface and associated individual meso-scale fractures were measured at the sample surface with respect to horizontal within the middle third of the specimen.

\subsection{Triaxial Testing Procedure}

The maximum applied principal stress was oriented approximately $85^{\circ} \pm 5^{\circ}$ to the bedding planes. Tests were performed at the Technical University of Graz (Austria) using a modified MTS 815 servo-hydraulic rock testing system with digital feedback control. All specimens were jacketed with a $0.5 \mathrm{~mm}$ thick DuPont FEP Fluorocarbon Film, and all tests were executed with impervious endplates (e.g., undrained). 


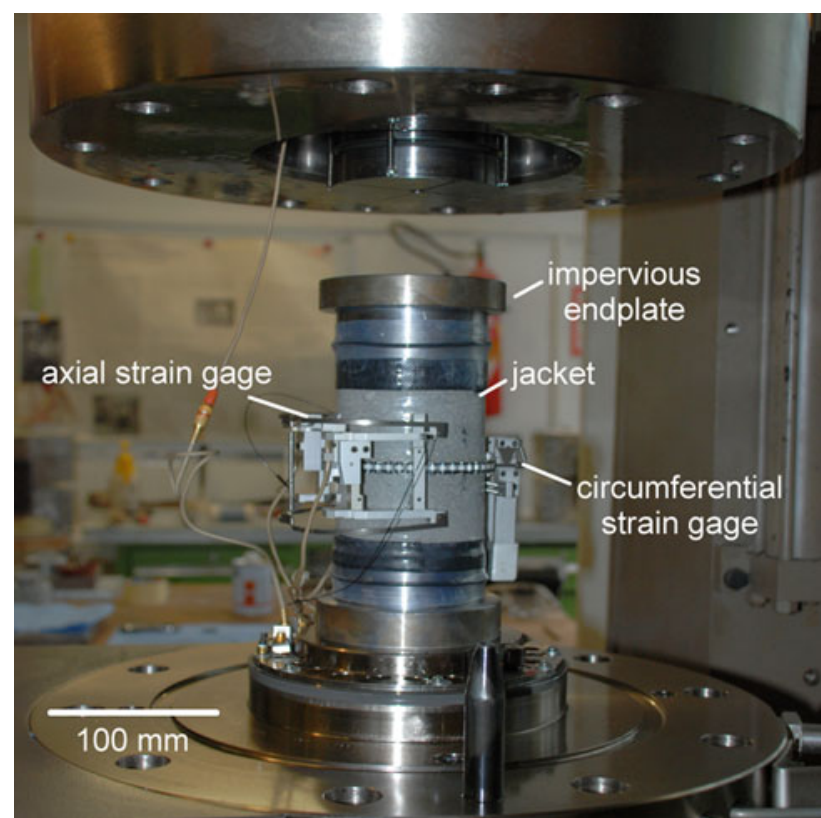

Fig. 3 Experimental set-up of the triaxial tests

Two axial strain gages (Type MTS Model 632.11F-90, Fig. 3), each with a measurement base-length of $50 \mathrm{~mm}$, were firmly attached on opposite sides of the specimens. Circumferential strain $\left(\varepsilon_{\text {circ }}\right)$ was measured by a single strain gage (Type MTS Model 632.21) attached to a chain wrapped tightly around the specimen. ${ }^{1}$ Volumetric strain $\left(\varepsilon_{v}\right)$ was calculated from the arithmetic mean of the two axial strains $\left(\varepsilon_{\text {axial }}\right)$ and the circumferential strain.

The confining stresses were chosen to investigate the transition from axial splitting to macroscopic shear failure. The following two aspects were considered for defining the confining stress range: (1) the in situ stress conditions are reasonably well defined at the Mont Terri URL. The major principal stress $\sigma_{1}$ is approximately $6.5 \mathrm{MPa}$ and sub-vertical, the sub-horizontal intermediate $\left(\sigma_{2}\right)$ and minor principal stresses $\left(\sigma_{3}\right)$ are 4.0 and $2.2 \mathrm{MPa}$, respectively (Corkum and Martin 2007), and (2) major changes in failure mechanism and triaxial strength arise in the low confinement range. Kaiser and Kim (2008) showed that a major change in behavior occurred for brittle failing rocks at $\sigma_{3}<\mathrm{UCS} / 10$. The average UCS of OPA specimens is 6.9 $\mathrm{MPa}$ (Amann et al. 2011), and hence a change in triaxial failure mode was anticipated between $\sigma_{3}=0.5$ and 1.0 MPa. Based on these considerations the tests were performed with confining stresses from 0.25 to $4.0 \mathrm{MPa}$.

Two triaxial testing procedures were utilized: nine single-stage tests utilizing $\sigma_{3}$ of $0.25,0.5,1.0,2.0$ and 4.0 MPa, and two multi-stage tests (Fig. 4) with four subsequent $\sigma_{3}$ stages $(0.5,1.0,2.0$ and $4.0 \mathrm{MPa})$. The

\footnotetext{
${ }_{1}^{1}$ As sign convention compressive stress and contraction are denoted as positive.
}

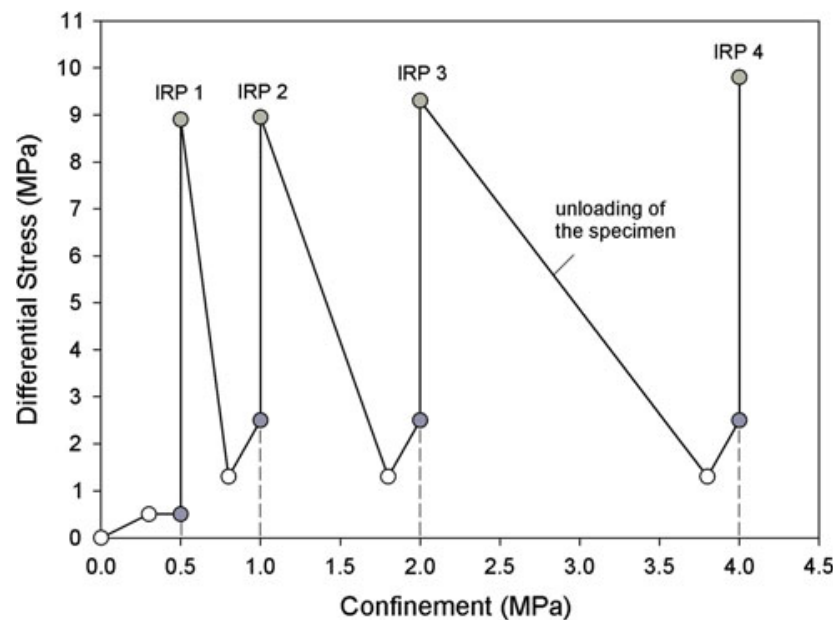

Fig. 4 Stress-path utilized for the multi-stage triaxial testing procedure (IRP imminent rupture point)

initial stress state was achieved in both testing procedures by the simultaneous increase of the axial and radial stress components. Axial stress was always kept $0.3 \mathrm{MPa}$ above the confining stress to avoid specimen lift-off.

During the test itself, the confining pressure was kept constant. The axial load was increased in such a way as to give a constant circumferential displacement rate of $0.08 \mathrm{~mm} / \mathrm{min}$. Single stage tests were manually stopped right after rupture to avoid extensive sample disintegration to allow for an assessment of the failure characteristics.

In case of multi-stage testing, the imminent rupture point (IRP) (Fig. 4) was automatically determined by the control unit when a drop of $0.2 \mathrm{MPa}$ in deviatoric stress occurred, or manually controlled when an IRP was approached. Subsequently to the detection of an IRP, the axial stress was reduced as confinement was increased in order to achieve a differential stress of $1.3 \mathrm{MPa}$ within $1 \mathrm{~s}$ (Fig. 4). Afterwards, the confinement and axial stress were increased simultaneously to the confining stress of the subsequent confinement stage, and confinement was again kept constant as the axial stress was increased. This procedure was four times repeated.

\subsection{Determination of the Damage Initiation Threshold}

The crack initiation stress threshold was determined by the point where the stress-volumetric strain curve departs from the linear elastic trend defined at lower stress levels (Brace et al. 1966, Fig. 5). As shown by Amann et al. (2011), the crack initiation threshold obtained from the stress-strain curves coincided with the onset of micro-acoustic activity and hence was a reliable indicator for damage initiation. The elastic modulus and Poisson's ratio were determined from the stress-strain curve by the least squares regression over the low stress range, where linear elastic behavior was 
Fig. 5 Methodology for defining the crack initiation threshold $\left(\sigma_{\mathrm{CI}}\right)$. a At confining stresses $\leq 1.0 \mathrm{MPa}$ the first evidence of departure from linearity was taken as the lower limit of $\sigma_{\mathrm{CI}}$. The upper limit of $\sigma_{\mathrm{CI}}$ was defined by a distinct stress drop. b At confining stresses $\geq 2.0 \mathrm{MPa}$ no stress drop occurred and $\sigma_{\mathrm{CI}}$ was defined from the first evident departure from linearity
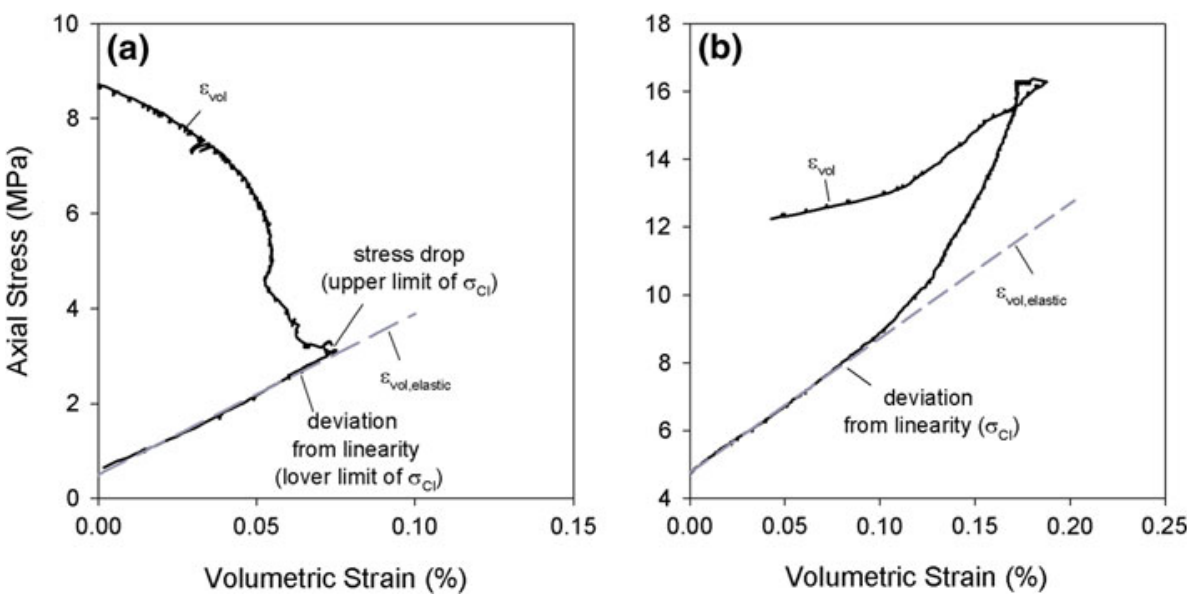

Table 1 Test type, water content $(\omega)$, compressive wave velocity parallel $\left(v_{p, \|}\right)$ and normal $\left(v_{p}, \perp\right)$ to bedding, total porosity $(\Phi)$ and degree of saturation $\left(S_{\mathrm{w}}\right)$

\begin{tabular}{lllllll}
\hline Specimen no. & Type & $\omega(\%)$ & $v_{p}, \perp(\mathrm{m} / \mathrm{s})$ & $v_{p, \|}(\mathrm{m} / \mathrm{s})$ & $\Phi$ & $S_{\mathrm{w}}$ \\
\hline 214.20 & MS & 7.75 & 2,343 & 2,993 & 0.18 & 1.00 \\
214.24 & MS & 7.67 & 2,301 & 3,106 & 0.18 & 1.00 \\
214.38 & SS & 7.59 & 2,363 & 3,100 & 0.18 & 1.00 \\
214.39 & SS & 7.59 & 2,408 & 3,131 & 0.27 & 0.68 \\
214.40 & SS & 7.26 & 1,756 & 3,045 & 0.16 & 1.00 \\
214.41 & SS & 7.26 & 2,220 & 2,973 & 0.17 & 1.00 \\
214.42 & SS & 7.51 & 1,830 & 3,033 & 0.18 & 1.00 \\
214.49 & SS & 7.57 & 2,370 & 3,010 & 0.18 & 1.00 \\
214.43 & SS & 7.51 & 2,396 & 3,075 & 0.18 & 1.00 \\
214.44 & SS & 7.88 & 2,301 & 3,005 & 0.18 & 1.00 \\
214.48 & SS & 7.57 & 2,416 & 3,014 & 0.18 & 1.00 \\
\hline
\end{tabular}

All physical rock properties were determined before testing

$M S$ multi-stage triaxial test, $S S$ single stage triaxial test

evident. As suggested by Amann et al. (2011), the first evidence of departure from linearity was taken as the lower limit of $\sigma_{\mathrm{CI}}$. The upper limit of $\sigma_{\mathrm{CI}}$ was defined by a distinct stress drop that typically occurred in this study when $\sigma_{3}$ was $\leq 1 \mathrm{MPa}$ (Fig. 5a). For all specimens the mean was defined as the crack initiation stress. In case no stress drop occurred (e.g., $\sigma_{3} \geq 2 \mathrm{MPa}$, Fig. $5 \mathrm{~b}$ ), no upper limit of the crack initiation threshold was determined.

\section{Triaxial Test Results}

\subsection{Specimen Characterization}

Macroscopic assessments revealed material heterogeneities in form of silty or sandy nodules in specimen No. 214.40. The other specimens were macroscopically homogeneous. The average water content of the test specimens was $7.59 \%$

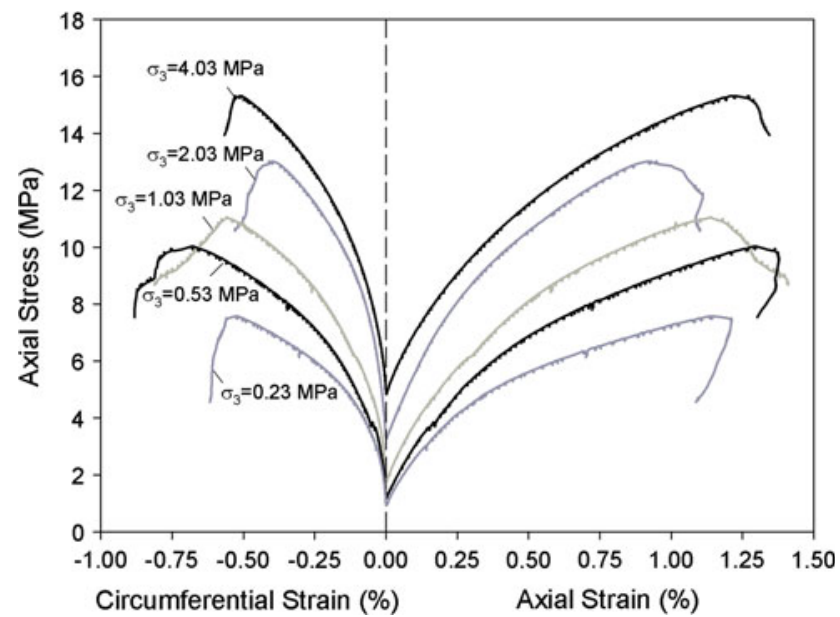

Fig. 6 Axial and radial strain behavior at different confining stress levels

with a maximum of $7.88 \%$ and a minimum of $7.26 \%$ (Table 1). The saturation was estimated as $100 \%$ for 14 specimens, and $68 \%$ for one specimen (No. 214.39; Table 1). The measured ultrasonic $\mathrm{P}$-wave velocities are summarized in Table 1 . The anisotropy ratio of $\mathrm{P}$-wave velocities was on average 1.36 with the velocity parallel to bedding being higher.

\subsection{Stress-Strain Relationship}

The stress-strain curves measured during the tests on specimen No. 214.38, 214.40, 214.42, 214.43 and 214.44 are shown in Fig. 6. These stress-strain curves are typical for all tested specimens.

This study on triaxial compression of OPA specimens revealed almost linear behavior at low differential stress levels (e.g., $\sigma_{\mathrm{D}}=\sigma_{1}-\sigma_{3}<2 \mathrm{MPa}$ ). On average the elastic modulus $(E)$ obtained from first loading was found to be $2.3 \mathrm{GPa}$ with a minimum of $1.3 \mathrm{GPa}$ and a maximum of $2.8 \mathrm{GPa}$. The Poisson's ratio ranged between 0.13 and 0.25 
with a mean value of 0.18 (Table 1 ). The lowest $E$ and highest Poisson's ratio was found for specimen No. 214.44. The reasons for the difference in $E$ and Poisson's ratio could not be related to visible sample disturbance or substantial differences in P-wave velocities and are currently unclear.

The continuous increase of $E$ associated with increasing $\sigma_{3}$ as observed by Corkum and Martin (2007) on consolidated undrained triaxial test results on OPA was not confirmed in this study. Even though, the average $E$ obtained from confined test results was higher than the modulus obtained from unconfined specimens (1.7 GPa; Amann et al. 2011). This might be due to the larger number of specimens utilized for unconfined compression tests.

In the confining stress range between 0.25 and $1.0 \mathrm{MPa}$, the linear elastic behavior was terminated by a distinct departure of the volumetric strain curve from linearity (Fig. 5a), associated with a stress drop similar to tests on unconfined specimens (Amann et al. 2011). For $\sigma_{3}=1 \mathrm{MPa}$, the departure from linearity was gradual but still associated with a minor stress drop. At $\sigma_{3} \geq 2.0 \mathrm{MPa}$, no stress drop was observed (Fig. 5b).

The differential stress at $\sigma_{\mathrm{CI}}\left(\sigma_{\mathrm{D}, \mathrm{CI}}\right)$ obtained from all specimens showed minimal scatter, and ranged between 1.9 and 2.4 MPa with a mean value of 2.1 MPa (Table 2). Figure $7 \mathrm{a}$ shows the differential stress at $\sigma_{\mathrm{CI}}$ plotted against confinement. It can be seen that $\sigma_{\mathrm{CI}, \mathrm{D}}$ is independent of the confining stress. Even though, the axial stress magnitude at $\sigma_{\mathrm{CI}}$ depends on confinement (Fig. 7b).

Crack initiation occurred on average at an axial strain of $0.059 \%$ and a circumferential strain of $0.011 \%$ (mean value

Table 2 Modulus of elasticity $(E)$ and Poisson's ratio (v), confining stress $\left(\sigma_{3}\right)$, rupture stress $\left(\sigma_{\text {rup }}\right)$, differential stress at failure $\left(\sigma_{\mathrm{D}}\right)$, crack initiation stress taken from the stress-strain response $\left(\sigma_{\mathrm{CI}}\right)$ and differential stress at crack initiation stress $\left(\sigma_{\mathrm{D}, \mathrm{CI}}\right)$

\begin{tabular}{llllllll}
\hline $\begin{array}{l}\text { Specimen } \\
\text { no. }\end{array}$ & $E$ & $v$ & $\begin{array}{l}\sigma_{3} \\
(\mathrm{MPa})\end{array}$ & $\begin{array}{l}\sigma_{\text {rup }} \\
(\mathrm{MPa})\end{array}$ & $\begin{array}{l}\sigma_{\mathrm{D}} \\
(\mathrm{MPa})\end{array}$ & $\begin{array}{l}\sigma_{\mathrm{CI}} \\
(\mathrm{MPa})\end{array}$ & $\sigma_{\mathrm{D}, \mathrm{CI}}$ \\
\hline 214.20 & 2,318 & 0.13 & Var. $^{\mathrm{a}}$ & $9.6^{\mathrm{b}}$ & $9.1^{\mathrm{b}}$ & $2.4^{\mathrm{b}}$ & $1.9^{\mathrm{b}}$ \\
214.24 & 2,690 & 0.14 & Var. $^{\mathrm{a}}$ & $8.9^{\mathrm{b}}$ & $8.4^{\mathrm{b}}$ & $2.7^{\mathrm{b}}$ & $2.1^{\mathrm{b}}$ \\
214.38 & 2,156 & 0.25 & 4.03 & 15.3 & 11.3 & 6.4 & 2.3 \\
214.39 & 2,378 & 0.19 & 4.03 & 16.4 & 12.3 & 6.1 & 2.0 \\
214.40 & 2,502 & 0.18 & 2.03 & 13.0 & 11.00 & 4.3 & 2.3 \\
214.41 & 2,600 & 0.15 & 2.03 & 12.4 & 10.4 & 4.1 & 2.0 \\
214.42 & 2,286 & 0.19 & 1.03 & 11.0 & 10.0 & 3.2 & 2.2 \\
214.49 & 2,818 & 0.17 & 1.03 & 11.8 & 10.8 & 3.1 & 2.1 \\
214.43 & 1,920 & 0.19 & 0.53 & 10.0 & 9.5 & 2.7 & 2.2 \\
214.44 & 1,300 & 0.17 & 0.28 & 7.6 & 7.3 & 2.5 & 2.2 \\
214.48 & 2,373 & 0.20 & 0.28 & 9.0 & 8.8 & 2.6 & 2.4 \\
\hline
\end{tabular}

a $0.5,1.0,2.0,4.0 \mathrm{MPa}$

${ }^{\mathrm{b}}$ First loading stage with $\sigma_{3}=0.5 \mathrm{MPa}$ does not include specimen No. 214.44 with a substantially lower $E$ ).

With increasing deviatoric stress beyond $\sigma_{\mathrm{CI}}$ the volumetric strain curves deviated steadily from linearity. For specimens with $\sigma_{3} \leq 1.0 \mathrm{MPa}$, the net volumetric strain was contractive up to a deviatoric stress where volumetric strain reversal occurred (Fig. 8). At rupture, the net volumetric strain was negative (extension) for all specimens tested with $\sigma_{3} \leq 0.5 \mathrm{MPa}$. For specimens with $\sigma_{3} \geq 1.0 \mathrm{MPa}$, the volumetric strain at rupture was positive (e.g., approximately $0.02 \%$, Fig. 8). At $\sigma_{3} \geq 2 \mathrm{MPa}$, contraction was observed over the entire pre-rupture stress range.

The rupture strength was dependent on $\sigma_{3}$. For specimens with $\sigma_{3}<1 \mathrm{MPa}$, minimal increases in $\sigma_{3}$ were associated with a larger increase in $\sigma_{\text {rup }}$ compared to the confining stress range $\geq 1 \mathrm{MPa}$. The triaxial strength determined from the multi-stage tests deviate with the number of loading stages increasingly from the rupture stress obtained from the single-stage tests. However, strength values taken from the first loading stage are in good agreement with the single-stage tests.

Specimens rupture was associated with a sudden axial stress drop. At rupture, the average axial and circumferential strain was 1.11 and $-0.53 \%$, respectively (Fig. 6). The axial strain at rupture stress showed almost no dependency on $\sigma_{3}$. However, the strain ratio at rupture stress $\left(\varepsilon_{\text {circ }} / \varepsilon_{\text {ax }}\right)$ decreases with increasing $\sigma_{3}$ indicating that the circumferential strain is inhibited with increasing $\sigma_{3}$ (Fig. 9).

\subsection{Failure Mechanism}

Amann et al. (2011) discussed the brittle failure behavior of unconfined OPA specimens loaded normal to bedding and found that the failure process is associated with axial fractures oriented sub-parallel to the loading direction, and bedding-parallel side-steps, which were interpreted as shears. The ultimate macroscopic failure surface of unconfined specimens was stepped at a typical inclination of $70-80^{\circ}$ from the horizontal (axial split).

Figure 10 shows the change in the macroscopic failure surface inclination (from horizontal) measured in the central third of the specimens. It can be seen that the overall inclination of the failure surface decreases with increasing $\sigma_{3}$. Detailed analyses showed, that the failure surface at $\sigma_{3}<0.5 \mathrm{MPa}$ consists of steep, $85-90^{\circ}$ inclined axial cracks on the $\mathrm{mm}$ - to cm-length scale and bedding-parallel side-steps on the mm-length scale (Fig. 11a; on average bedding was $5^{\circ}$ inclined from horizontal).

With increasing $\sigma_{3}$, the decrease in macroscopic inclination of the failure surface was related to more frequent and longer side-steps together with shortening of axial cracks. 
Fig. 7 a Differential stress at crack initiation versus confinement, b crack initiation stress in a principal stress diagram. The relationship in $\mathbf{b}$ is defined by the empirical HoekBrown failure criterion
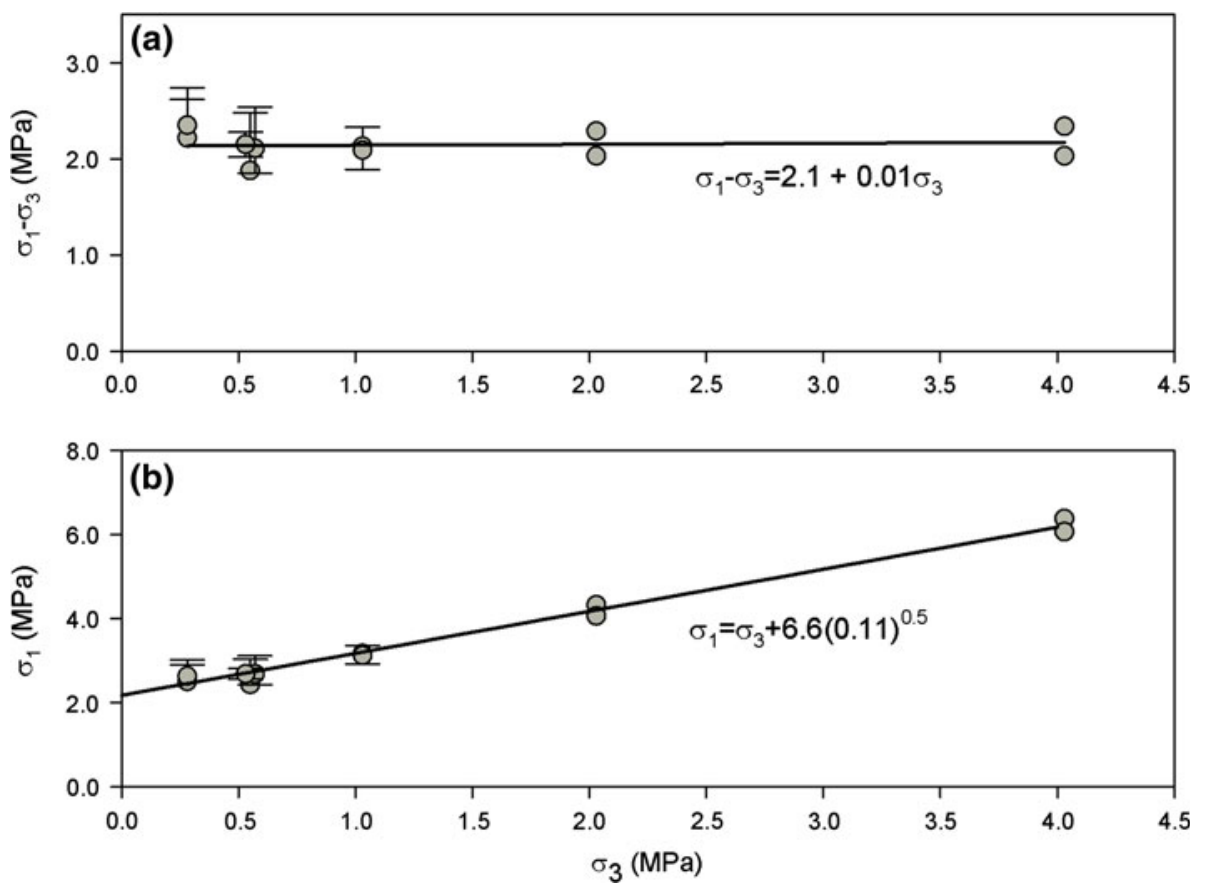

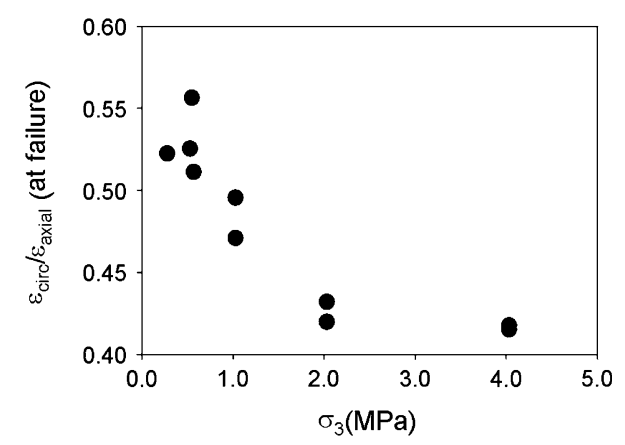

Fig. 9 Strain ratio for all specimens with axial and circumferential strain taken at failure

\section{Discussion}

Fig. 8 Volumetric strain versus axial stress behavior for different confining stresses in the pre-rupture phase. For confining stress $\geq 2.0 \mathrm{MPa}$ the volumetric behavior was purely contractive over the entire pre-rupture phase

At $\sigma_{3}=0.5 \mathrm{MPa}$ axial cracks and bedding-parallel side-steps still prevail, however, fractures inclined at $50-60^{\circ}$ started to appear (Fig. 11b). At $\sigma_{3}=1.0 \mathrm{MPa}$ the proportion of axial to inclined fractures became equal. Beyond 1.0 MPa confinement the meso-scale axial cracks disappeared entirely and the failure surface was composed of bedding-parallel side-steps and $50-60^{\circ}$ inclined fractures, both on the mm-length scale (Fig. 11c). In addition to the change in orientation of meso-scale fractures, the failure surface of specimens with $\sigma_{3} \geq 2 \mathrm{MPa}$ showed locally approximately $0.5 \mathrm{~mm}$ wide shear bands along the failure planes.

\subsection{Test Procedure}

Figure 12 shows the results obtained from multi-stage and single-stage triaxial tests. It can be seen that rupture stress determined with the multi-stage testing procedure increasingly deviate with the number of stages from the rupture stress values obtained from single-stage tests, or more appropriately the cumulative strain. The deviation towards lower $\sigma_{\text {rup }}$ associated with subsequent loading stages suggests that damage accumulates during the test procedure, and degrade the rupture strength relative to the strength obtain from single-stage tests. The friction coefficient shown in Fig. 12 was obtained from single-stage test results in the $\sigma_{3}$ range, where macroscopic shear failure was evident (e.g., $\sigma_{3} \geq 1.0 \mathrm{MPa}$; Fig. 13), and is assumed to be constant as suggested by Hajiabdolmajid and Kaiser 


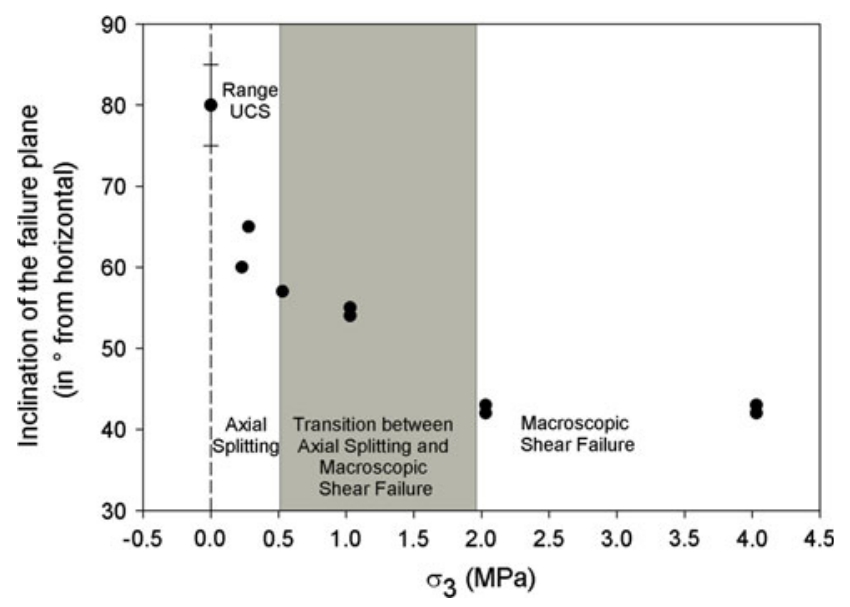

Fig. 10 Inclination of the macroscopic failure surface with respect to horizontal. Range of failure surface inclinations from unconfined compressive strength tests (UCS) is also indicated

(2003) and Hajiabdolmajid et al. (2002). Therefore, damage (as indicated by an arrow in Fig. 12) is entirely associated with loss of cohesion.

Since damage is initiated already in the first loading stage and accumulates during the pre-rupture phase of loading, the ultimate failure envelope of brittle failing OPA cannot adequately determined from multi-stage testing procedures. These data would result in a Mohr-Coulomb or Hoek-Brown failure criterion assessment with a lower frictional and cohesive component, and a lower ACS
(Fig. 13). However, results obtained from the first loading stage are suitable for comparison with single-stage tests. Nevertheless, subsequent stages provide some insight into the relatively constant contribution of the frictional strength component during the brittle failure processes. This was not further investigated in the present study.

\subsection{Stress-Strain Response}

The results of this study show that the differential stress at $\sigma_{\mathrm{CI}}$ has minimal scatter and is $2.1 \mathrm{MPa}$ on average (Table 2; Fig. 7a). Amann et al. (2011) showed that $\sigma_{\mathrm{CI}}$ from unconfined compression tests was $2.0 \mathrm{MPa}$ on average, and therefore is very similar to the findings from confined loading tests.

The confining stress independency of the differential stress at $\sigma_{\mathrm{CI}}$ found in this study coincides with findings obtained from crystalline rocks, which showed that microcrack initiation is only dependent on the differential stress, and is less sensitive to confinement as compared to the rupture stress (e.g., Brace et al. 1966; Scholz 1968). Studies on crystalline rock also showed that the coincidental mobilization of frictional and cohesive strength components, as assumed in the Mohr-Coulomb and Hoek-Brown failure criteria, is not valid for brittle failing rock under low confinement (Martin 1997; Martin et al. 1999; Martin and Chandler 1994; Diederichs 2003; Kaiser 1994; Hajiabdolmajid and Kaiser 2003). Under these conditions, most micro-cracks dilate upon propagation, inhibiting the
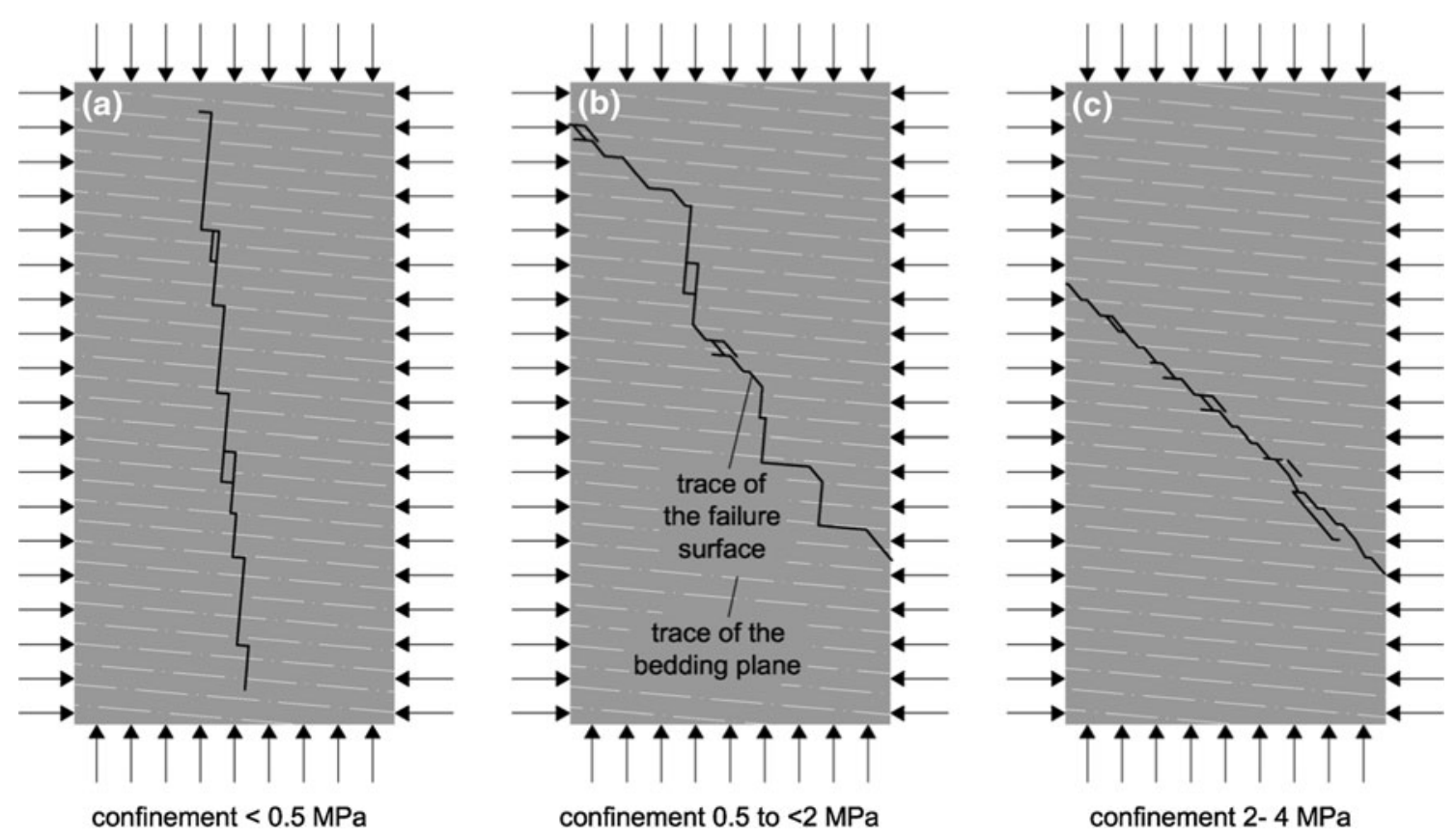

Fig. 11 Observed meso- and macro-scale failure surface characteristics typical for the confinement ranges $<0.5,0.5$ to 2 and 2 to 4 MPa. As confinement is increased the failure surface inclination decreases 


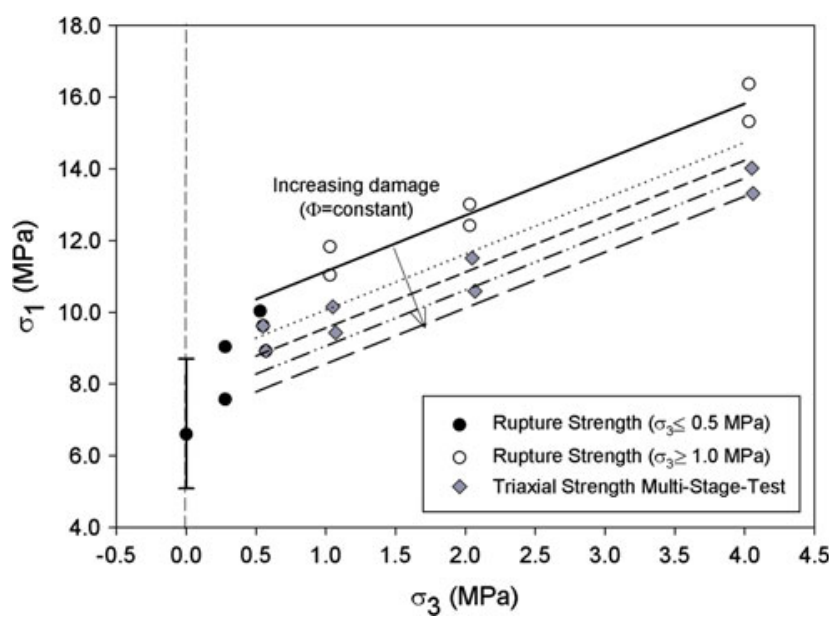

Fig. 12 Comparison between single-stage and multi-stage triaxial tests results. With increasing number of stages damage accumulates and is associated with a substantial degradation of the rupture stress. A constant friction angle $(\phi)$ was assumed

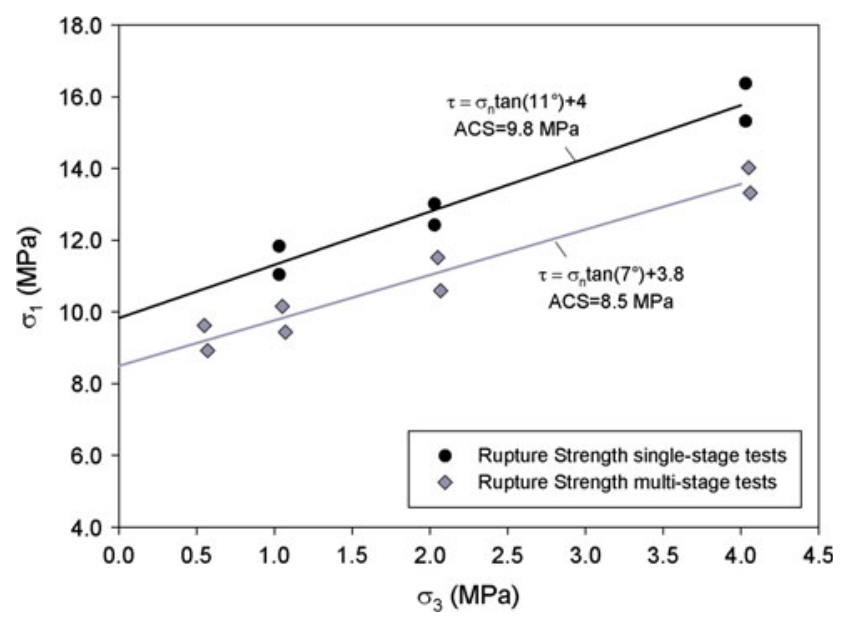

Fig. 13 Comparison between the Mohr-Coulomb strength properties and ACS based on least squares regression analyses of single-stage $\left(\sigma_{3} \geq 1 \mathrm{MPa}\right)$ and multi-stage triaxial tests. Since damage is initiated already in the first loading stage and accumulates during the prerupture phase of loading, the ultimate failure envelope of brittle failing OPA cannot adequately determined from multi-stage testing procedures. These data would result in a Mohr-Coulomb failure criterion assessment with non-representative values for the friction angle, the cohesion and ACS

development of frictional resistance. As confinement is applied, the orientation and magnitude of the load on a given plane increases, resulting in frictional resistance and the associated strength increase. Based on theoretical crack growth models it must be asked if the coincidental mobilization of frictional and cohesive strength is valid for brittle rock types undergoing failure at low confinement. Diederichs (2003) pointed out that as intact rock is strained, cohesive bonds fail first and damage accumulates. Frictional strength cannot be mobilized until the rock is sufficiently damaged and shearing begins on the newly developed micro-fractures. Martin et al. (1999) suggested that the crack initiation envelope of brittle failing rocks is best represented by assuming the constant $m$ of the empirical non-linear Hoek-Brown failure criterion equal to 0 (equivalent to $\phi=0^{\circ}$ in the Mohr-Coulomb shear failure criterion) and the cohesive strength component $s$ equal to 0.11 .

Figure $7 \mathrm{~b}$ shows the crack initiation stress thresholds obtained in this study in principal stress space together with a fitted Hoek-Brown failure envelope. The fit revealed for $m=0$ and for $s=0.11$, and the previously mentioned findings gained from crystalline rocks therefore do apply to OPA.

Amann et al. (2011) showed that the failure process of unconfined OPA is associated with axial cracks possibly emanating from bioclasts or form within more compliant bedding layers in a layered system with contrasting stiffness, and bedding-parallel side-steps. The visual assessment of the macro- and meso-scale failure surface characteristics from specimens with $\sigma_{3}<1 \mathrm{MPa}$ achieved in this study (Fig. 11a, b) correspond with the observations made on unconfined tests.

At $\sigma_{3} \geq 2 \mathrm{MPa}$ meso-scale axial cracks disappear entirely, and the failure surface is composed of beddingparallel side-steps, and $50-60^{\circ}$ inclined fractures, both on the mm-length scale (Fig. 11c). From visual observation, it is uncertain whether the inclined fractures are a consequence of the coalescence of multiple axial micro-cracks (Lockner et al. 1992) or shearing. Appropriate analyses utilizing Scanning Electron Microscopy are ongoing.

As shown in Fig. 8, the increase of the axial stress beyond $\sigma_{\mathrm{CI}}$ results in the stress-volumetric strain curve steadily deviating from linearity. A major difference in the volumetric strain behavior was observed below and above $2 \mathrm{MPa}$ confinement (Fig. 8). For $\sigma_{3}>2 \mathrm{MPa}$, the volumetric behavior was contractive in the entire pre-rupture stress range. In addition, the volumetric strain at the rupture stress was dilative for specimens with $\sigma_{3} \leq 0.5 \mathrm{MPa}$ and contractive for $\sigma_{3} \geq 1.0 \mathrm{MPa}$. Based on the definition of the volumetric strain for radial loading conditions, volumetric contraction can only be maintained when the axial strain is larger than two times the circumferential strain. From the stress-strain curves, it can be seen that the ratio of axial to radial strain obtained at rupture stress decreases non-linearly with increasing confinement (Fig. 9), while no clear trend towards larger axial failure strain was observed. This result suggests that circumferential strain at rupture becomes less negative with increasing confinement and the change in volumetric behavior is possibly associated with the suppression of dilatant fracturing probably related to a change in the failure mode or vice versa. This coincides with the observed meso-scale failure surface characteristics. Inclined 
fractures appeared at $0.5 \mathrm{MPa}$ confining stress, while axial cracks became shorter in length. At $\sigma_{3}=1 \mathrm{MPa}$ axial and inclined cracks were approximately averaged and radial strain became insufficient to generate net volumetric expansion in the pre-failure stage of loading. Axial cracks disappeared entirely at $\sigma_{3} \geq 2 \mathrm{MPa}$ (at least they are not visible with a binocular microscope), though dilation occurs.

In contrast to the slight dependency of $\sigma_{\mathrm{CI}}$ on confinement, $\sigma_{\text {rup }}$ was considerably dependent on confinement and suggests that the frictional strength component is mobilized during the brittle failure process. However, the dependency on confinement was different for $\sigma_{3} \leq 0.5$ and $\sigma_{3} \geq$ 1.0 MPa (Fig. 14). As shown in the previous sections, growth of axial and bedding-parallel fractures was the predominant failure mode when the confining stress was $\leq 0.5 \mathrm{MPa}$ (axial splitting), and macroscopic shear failure when confinement was $>1.0 \mathrm{MPa}$. The continuous change in the observed failure mechanism from splitting to macroscopic shear failure was associated with a substantial decrease in triaxial rupture stress below $\sigma_{3}=1.0 \mathrm{MPa}$, and a moderate increase above $\sigma_{3}=1.0 \mathrm{MPa}$.

The triaxial tests presented here were obtained undrained, which means that no change in the water content within the specimen occurs during the test. However, pore pressure can change. Aristorenas (1992) performed undrained triaxial tests on OPA in which pore pressure was measured. He found that pore pressure changes occurred that were associated with the volumetric strain (e.g., dilatancy) of the specimens, and thus have an influence on the effective strength. The pore pressure was not measured during the tests reported in this study and thus its influence on the failure process and strength remains unknown.

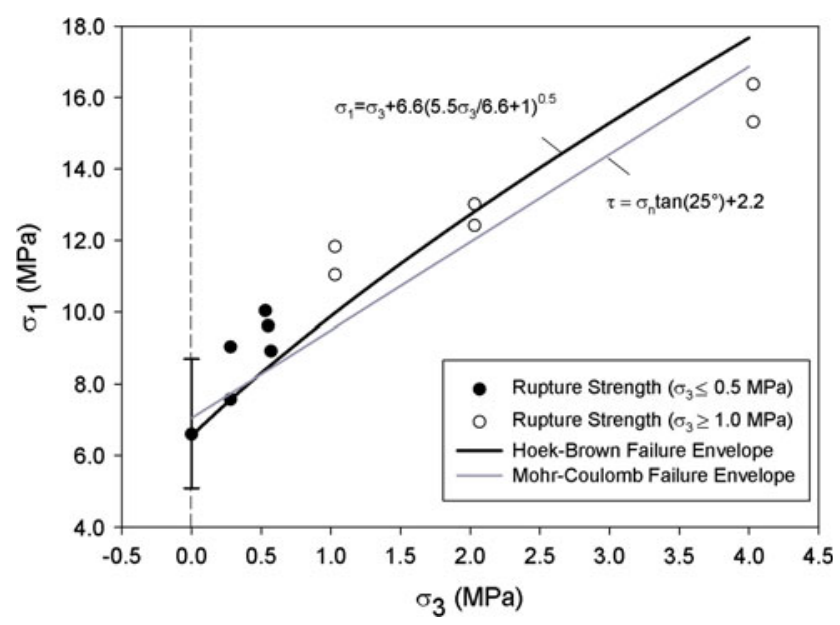

Fig. 14 Strength properties for the linear Mohr-Coulomb (friction coefficient and cohesion) and non-linear Hoek-Brown (constant $m$ and $s$ ) failure criterion based on rupture stress data of the entire confining stress range tested in this study based on least squares regression analyses

\subsection{Failure Envelope}

The data from this study was used to obtain the normal stress $\left(\sigma_{n}\right)$ dependent frictional and cohesive components of strength in the Mohr-Coulomb shear failure criterion $(\Phi$ : friction and $c$ : cohesion),

$\tau=\sigma_{n} \tan (\phi)+c$

and the constants $m$ and $s$ of the empirical non-linear Hoek-Brown failure criterion. The constant $a$ was assumed to be 0.5 .

$\sigma_{1}=\sigma_{3}+\mathrm{UCS}\left(m \frac{\sigma_{3}}{\mathrm{UCS}}+s\right)^{a}$.

For the UCS, a value of 6.6 MPa was used (instead of the average UCS of $6.9 \mathrm{MPa}$ as obtained by Amann et al. 2011). This value is justified because the highest UCS values obtained by Amann et al. (2011) were associated with heterogeneities, which most probably affected the unconfined strength.

Neither the linear Mohr-Coulomb (Eq. 1) nor the nonlinear Hoek-Brown failure criterion (Eq. 2) adequately captures the strength decrease below $\sigma_{3}=1.0 \mathrm{MPa}$ (Fig. 14). In the range of confining stresses utilized in this study both failure criterions under-predict the rupture stress for $\sigma_{3}<1 \mathrm{MPa}$ (Fig. 14). However, linear regression analyses of rupture strength data obtained at $\sigma_{3} \geq 1.0 \mathrm{MPa}$, where macroscopic shear failure occurred, revealed a coefficient of determination $\left(r^{2}\right)$ of 0.95 (Table 3). In contrast to the excellent coefficient of determination for confining stresses $\geq 1.0 \mathrm{MPa}$, the coefficient of regression at low confinement $(\leq 1 \mathrm{MPa})$ is rather poor $\left(r^{2}=0.57\right)$, and reflects the variability in strength within this confinement range. The variability in unconfined strength was discussed in Amann et al. (2011), and was related to the size, the amount, and the orientation of spatial distributed

Table 3 Coefficient of correlation $\left(r^{2}\right)$ and constitutive properties for the Mohr-Coulomb (MC) and the Hoek-Brown (HB) failure criterion

\begin{tabular}{lllllll}
\hline & $\begin{array}{l}r^{2} \\
(-)\end{array}$ & $\begin{array}{l}\mathrm{UCS} \\
(\mathrm{MPa})\end{array}$ & $\Phi\left(^{\circ}\right)$ & $c(\mathrm{MPa})$ & $\begin{array}{l}m \\
(-)\end{array}$ & $\begin{array}{l}s \\
(-)\end{array}$ \\
\hline $\mathrm{MC}($ all data $)$ & 0.85 & $7.0^{\mathrm{a}}$ & 25 & 2.2 & - & - \\
$\mathrm{MC}\left(\sigma_{3} \geq 1.0 \mathrm{MPa}\right)$ & 0.95 & $9.8^{\mathrm{a}}$ & 11 & 4.0 & - & - \\
$\mathrm{MC}\left(\sigma_{3} \leq 1.0 \mathrm{MPa}\right)$ & 0.56 & $6.7^{\mathrm{a}}$ & 43 & 1.45 & - & - \\
$\mathrm{HB}($ all data $)$ & 0.57 & $6.6^{\mathrm{b}}$ & - & - & 4.4 & 1 \\
$\mathrm{HB}\left(\sigma_{3} \geq 1.0 \mathrm{MPa}\right)$ & 0.65 & $9.8^{\mathrm{a}}$ & - & - & 1.3 & 1 \\
$\mathrm{HB}\left(\sigma_{3} \leq 1.0 \mathrm{MPa}\right)$ & 0.43 & $6.6^{\mathrm{b}}$ & - & - & 10.3 & 1 \\
\hline
\end{tabular}

UCS Uniaxial Compressive Strength, $\Phi$ friction angle, $c$ cohesion, $m, s$ Hoek-Brown constants

${ }^{a}$ Uniaxial Compressive Strength obtained from back-extrapolation (ACS)

b Mean Uniaxial Compressive Strength obtain in the laboratory (Amann et al. 2011) 
heterogeneities, which may have an influence on the probability that micro-cracks coalesce. In addition, the confinement dependency on the length of a growing tensile microcrack (Hoek 1965) may probably influence the strength variability for materials with isolated heterogeneities. As confinement is increased, the absolute length of axial microcracks is suppressed as suggested by Hoek (1965), and the probability for forming a dominant single crack due to coalescence decreases, at the same time the frictional resistance due to contacting crack walls increases resulting in a change in failure mechanism and rupture strength as observed in this study.

The data presented in Fig. 14 suggest that a bi-linear failure envelope is required to capture the rupture strength over the entire confining stress range (Fig. 15). The linear regression analysis on strength data at $\sigma_{3} \leq 1 \mathrm{MPa}$ revealed an ACS close to the UCS determined from unconfined tests. The ACS taken from strength data at $\sigma_{3} \geq 1 \mathrm{MPa}$, however, was 1.5 times higher than UCS. The factor is in the range of values obtained by Kaiser and Kim (2008) for different types of brittle failing rocks.

Kaiser and Kim (2008) suggested that the general form of the Hoek-Brown failure envelope (Eq. 2), with an unusually high value for $m$, for example $m>50$, and $a \neq 0.5$, may also provide a reasonable fit for intact rock strength across the entire range of confinement. The least squares regression analyses of the data obtained in this study revealed a value of $m=91.5$ and $a=0.15$ (Fig. 16).

Both, the bi-linear and the generalized Hoek-Brown failure envelopes provide a reasonable fit to the data when $\sigma_{3}$ is compressive. Even though the tensile strength obtained by back-extrapolation into the tensile region underestimates the tensile strength of OPA. Brazilian tests

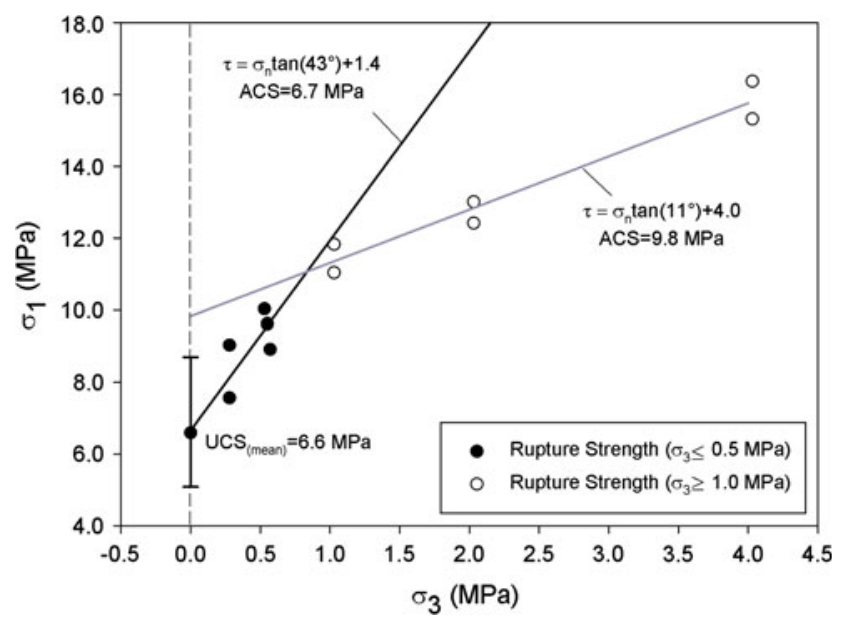

Fig. 15 Least squares regression analyses for strength properties of a bi-linear Mohr-Coulomb failure criterion utilizing the confining stress ranges $0-0.5$ and $1.0-4.0 \mathrm{MPa}$ on a series of OPA specimens at natural water content by Wild (2010) revealed that the Brazilian tensile strength parallel to bedding ranges between 1.4 and $2.0 \mathrm{MPa}$ (1.7 MPa on average). Back-extrapolation of the bi-linear failure criterion (e.g., the linear failure envelope fitting the strength data at $\sigma_{3} \leq 1.0 \mathrm{MPa}$, Fig. 15) predicts a tensile strength of 1.26 MPa, and in the generalized Hoek-Brown envelope, a tensile strength of $0.072 \mathrm{MPa}$. In the latter case, the tensile strength is an order of magnitude smaller than the measured value, therefore leading to a significant underestimation.

Kaiser and Kim (2008) developed an empirical failure criterion for brittle failing rock utilizing UCS, ACS, the spalling limit $\left(k_{s}\right.$; here defined as $\left.\sigma_{1} / \sigma_{3}\right)$ and the fitting parameter $\sigma_{3}^{0}$ and $\delta \sigma_{3}$ :

$\sigma_{1}=k_{S} \sigma_{3}+\mathrm{ACS}+\left[\frac{(\mathrm{UCS}-\mathrm{ACS})}{1+\mathrm{e}^{\left(\sigma_{3}-\sigma_{3}^{0}\right) / \delta \sigma_{3}}}\right]$.

In Fig. 17 this S-shaped empirical failure criterion was applied on the data obtained in this study, taking $\mathrm{UCS}=6.6 \mathrm{MPa}, \mathrm{ACS}=9.8 \mathrm{MPa}$ and a spalling limit of 15 to 20 (Table 4). The S-shaped failure criterion fits the data obtained in this study well and captures the rupture strength over the entire confining stress range. However, this empirical failure criterion tends to over-predict the tensile strength (e.g., back-extrapolation into the tensile region results in a tensile strength of $4.4 \mathrm{MPa}$ ), and therefore a "tension cut-off" should be considered (Goodman 1980).

Both, the bi-linear and the S-shaped failure envelope provide a reasonable fit to the rupture stress data reported in this study. However, as stated in the previous section the tests were obtained undrained and the influence of pore pressure changes on the effective strength remain unknown.

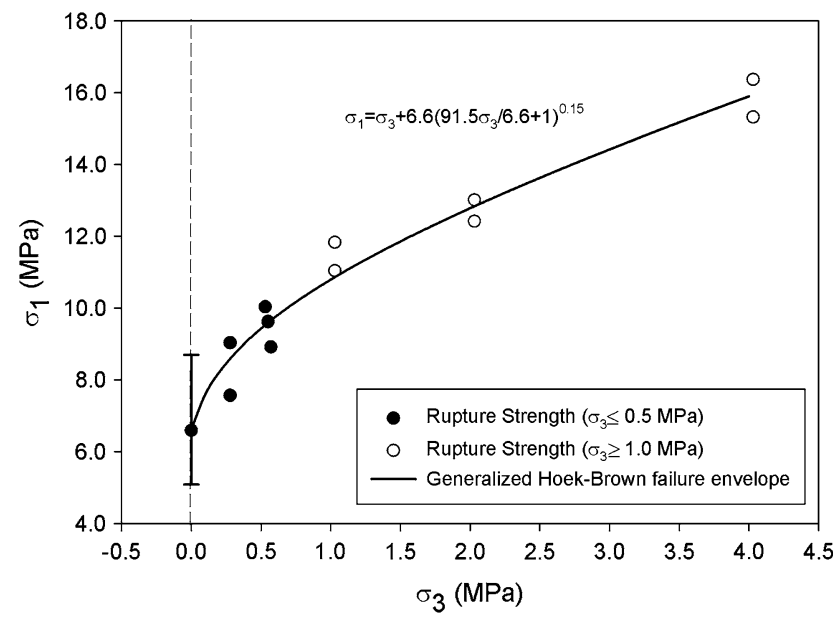

Fig. 16 Least squares regression analyses for strength properties of a generalized Hoek-Brown failure criterion $(m=91.5$ and $a=0.15)$ 


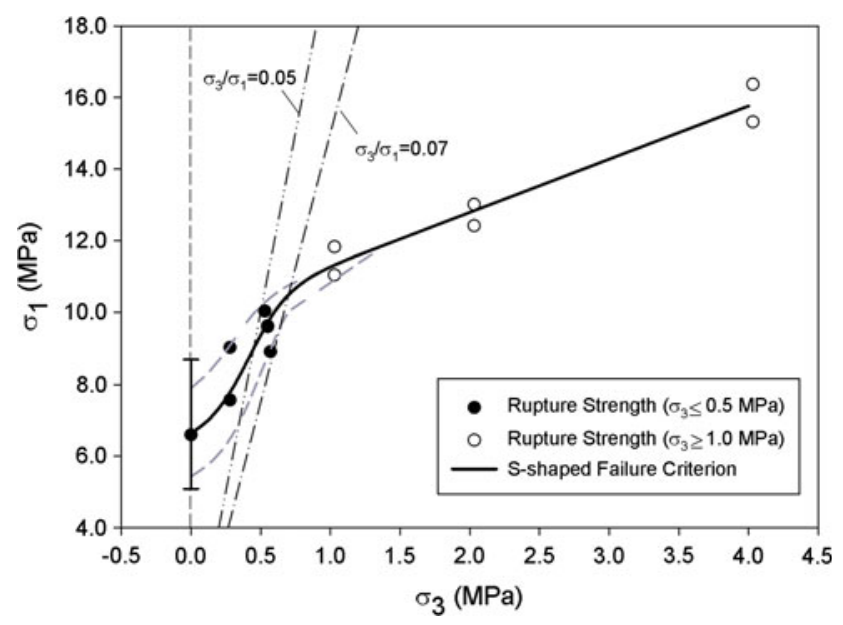

Fig. 17 S-shaped failure criterion developed by Kaiser and Kim (2008) utilizing least squares regression analyses. The dashed lines represent a lower and upper bound of the failure envelope taking the constitutive properties in Table 4

Table 4 Constitutive properties for the S-shaped failure criterion (Fig. 14) developed by Kaiser and Kim (2008)

\begin{tabular}{llllll}
\hline & $\begin{array}{l}\text { UCS } \\
(\mathrm{MPa})\end{array}$ & $\begin{array}{l}\text { ACS } \\
(\mathrm{MPa})\end{array}$ & $\begin{array}{l}k_{s} \\
\left({ }^{\circ}\right)\end{array}$ & $\begin{array}{l}\sigma_{3}^{0} \\
(\mathrm{MPa})\end{array}$ & $\begin{array}{l}\delta \sigma_{3} \\
(-)\end{array}$ \\
\hline Best fit & 6.6 & 9.8 & 20 & 0.14 & 0.42 \\
Lower bound & 5.3 & 9.8 & 15 & 0.14 & 0.50 \\
Upper bound & 7.7 & 9.8 & 15 & 0.14 & 0.30 \\
\hline
\end{tabular}

UCS Uniaxial Compressive Strength, ACS apparent unconfined compressive strength, $k_{s}$ spalling limit, $\sigma_{3}^{0}$ and $\delta \sigma_{3}$ are fitting parameter

\section{Conclusions}

The study of the brittle failure behavior of clay shale in triaxial compression showed that failure is initiated at a consistent differential stress of $2.1 \mathrm{MPa}$. This suggests that friction mobilization is negligible at this stage of brittle failure.

It was also shown, that the volumetric behavior in the pre-rupture phase is dependent on the confining stress. At low confining stress (e.g., $\sigma_{3} \leq 0.5 \mathrm{MPa}$ ) volumetric strain at rupture was negative (expansion). With increasing confinement, dilation was suppressed at failure. For $\sigma_{3} \geq 2 \mathrm{MPa}$ volumetric strain reversal entirely disappeared. The differences in volumetric behavior are possibly associated with the suppression of dilatant fracturing and a related change in the failure mode.

Macro- and meso-scale assessment of the rupture surface showed a decreasing inclination with respect to the horizontal with increasing confinement. It was observed, that the stepped, steeply inclined failure plane at $\sigma_{3}<0.5$ was an assembly of axial cracks and bedding-parallel sidesteps (possibly shears). With increasing confinement, the length of axial cracks became shorter while bedding parallel shears became longer. With further increase in confinement inclined fractures appeared while axial fractures were not visible. The data suggest a transition from axial splitting to macroscopic shear failure as confinement is increased.

In contrast to the differential stress at the crack initiation threshold, rupture stress was dependent on confinement, which suggests that friction was mobilized during the failure process. However, the dependency on confining stress cannot be adequately represented by a linear MohrCoulomb or a non-linear Hoek-Brown shear failure envelope. The data suggest the use of a bi (or tri)-linear or S-shaped (Kaiser and Kim 2008) failure envelope to account for the changes in fracture processes.

Acknowledgments This study was funded by the Swiss Federal Nuclear Safety Inspectorate (ENSI). The authors are grateful to R. Thoeny (ETH Zurich) and M. Bluemel (Graz Technical University) for help and useful discussion provided during the laboratory work and data interpretation. We also like to thank Prof. Dr. Derek Martin and Nathan Deisman (University of Alberta, Canada) for the instructive discussions.

\section{References}

Amann F, Button EA, Evans KF, Gischig VS, Blümel M (2011) Experimental study of the brittle behavior of clay shale in shortterm unconfined compression. Rock Mech Rock Eng (In Review)

Aristorenas GV (1992) Time-depended behavior of tunnels excavated in shale. PhD-thesis, Department of Civil Engineering, Massachusetts Institute of Technology, Massachusetts

Ashby MF, Hallam SD (1986) The failure of brittle solids containing small cracks undercompressive stress states. Acta Metall 34(3):497-510

Bieniawski ZT (1967) Mechanism of brittle failure of rock Part I-Theory of fracture process. Int J Rock Mech Min Sc Geomech Abstr 4(4):395-406

Bobet A, Einstein HH (1998) Fracture coalescence in rock-type materials under uniaxial and biaxial compression. Int $\mathrm{J}$ Rock Mech Min Sci 35(7):863-889

Bock H (2008) RA experiment-updated review of the rock mechanics properties of the Opalinus Clay of the Mont Terri URL based on laboratory and field testing, Mont Terri Technical Report 2008-04

Brace WF, Paulding BR, Scholz C (1966) Dilatancy in fracture of crystalline rocks. J Geophys Res 71(16):3939-3953

Cook NGW (1965) The Failure of Rock. Int J Rock Mech Min Sci 2:389-403

Corkum AG, Martin CD (2007) Modelling a mine-by test at the Mont Terri rock laboratory, Switzerland.Int J Rock Mech Min Sci 44:846-859

Diederichs MS (2003) Rock fracture and collapse under low confinement conditions. Rock Mech Rock Eng 36(5):339-381

Germanovich LN, Dyskin AV (1988) A model of brittle failure for materials with cracks in uniaxial loading. Mech Solids 23(2):111-123

Goodman RE (1980) Introduction to rock mechanics, John Wiley \& Sons, New York 
Hajiabdolmajid VR, Kaiser PK (2003) Mobilized strength components in brittle failure of rock. Géotechnique 53(3):237-336

Hajiabdolmajid V, Kaiser PK, Martin CD (2002) Modelling brittle failure of rock. Int J Rock Mech Min Sci 39(6):731-741

Hallbauer DK, Wagner H, Cook NGW (1973) The microscopical and mechanical behaviour of Quartzite specimens in stiff, triaxial compression tests. Int J Rock Mech Min Sc Geomech Abstr 10:713-726

Hoek E(1965) Rock fracture under static stress conditions. PhD thesis, University of Cape Town

Horii H, Nemat-Nasser S (1985) Compression-induced microcrack growth in brittle solids: axial splitting and shear failure. J Geophys Res 90:3105-3125

ISRM (1979) Suggested methods for determining water content, porosity, density, absorption and related properties and swelling and slake-durability index properties. Int J Rock Mech Min Sc Geomech Abst 16(2):141-156

Jaeger JC (1960) Rock failure at low confining pressures. Engineering 189:283-284

Kaiser PK (1994) Rockmass failure and implications for support design. Symposium on tunnelling in difficult ground, Torino, Italy 9-1-9-8

Kaiser PK, Kim BH (2008) Rock mechanics advances of underground construction and mining. Korea Rock Mech, Seoul, Korea 1-16

Kaiser PK, Diederichs MS, Martin CD, Sharp J, Steiner W (2000) Underground works in hard rock tunneling and mining. GeoEng2000, Melbourne

Kemeny JM, Cook NGW (1986) Effective moduli, non-linear deformation and strength of a cracked elastic solid. Int J Rock Mech Min Sci Geomech Abstr 23(2):107-118

Klinkenberg M, Kaufhold S, Dohrmann R, Siegesmund S (2009) Influence of carbonate micofabric on the failure strength of claystones. Eng Geol 107:42-54

Lajtai EZ, Lajtai VN (1974) The evolution of brittle fracture in rock. J Geol Soc 130:1-16
Lajtai EZ, Carter BJ, LAyari M (1990) Criteria for brittle fracture in compression. Eng Fracture Mech 37:59-74

Lockner DA, Moore DE, Reches Z (1992) Microcrack interaction leading to shear fracture. In: Tillerson and Wawersik (eds) 33rd US Rock Mechanics Symposium 908-816

Marschall P, Horseman S, Gimmi T (2005) Characterisation of gas transport properties of the opalinus clay, a potential host rock formation for radioactive waste disposal. Oil Gas Sci TechnolRev IFP 60(1):121-139

Martin CD (1997) Seventeenth Canadian Geotechnical Colloquium: The effects of cohesion loss and stress path on brittle rock strength. Can Geotech J, 34:698-725

Martin CD, Chandler NA (1994) The progressive fracture of Lac du Bonnet granite. Int J Rock Mech Min Sc 31:643-659

Martin CD, Kaiser PK, McCreath DR (1999) Hoek-Brown parameters for predicting the depth of brittle failure around tunnels. Can Geotech J 36(1):136-151

Paterson M (1958) Experimental deformation and faulting in Wombeyan marble. Geol Soc Am Bull 69:465-476

Sammis CG, Ashby MF (1986) The failure of brittle porous solids under compressive stress states. Acta Metall 34(3):511-526

Scholz CH (1968) Experimental study of the fracturing process in brittle rock. J Geophys Res 73(4):1447-1454

Steiner W, Kaiser PK, Spaun G (2010) Role of brittle fracture on swelling behavior of weak rock tunnels: hypothesis and qualitative evidence. Geomech Tunn 3(5):583-596

Thury M, Bossart P (1999) Mont Terri rock laboratory, results of the hydrogeological, geochemical and geotechnical experiments performed in 1996 and 1997. Landeshydrologie und -geologie, Geologischer Bericht Nr. 23

Underwood LB (1967) Classification and identification of shales. J of the Soil Mech Found Div, Proc Am Soc Civil Eng 97-116

Wild K (2010) Charakterisierung des Verhaltens von Opalinuston unter Zugbeanspruchung, Bsc thesis, ETH Zurich, Switzerland 